\title{
High-Fat Diet-Induced Adipose Tissue and Liver Inflammation and Steatosis in Mice Are Reduced by Inhibiting Sialidases
}

Darrell Pilling, Tejas R. Karhadkar, and Richard H. Gomer

From the Department of Biology, Texas A\&M University, College Station, Texas

\author{
Accepted for publication \\ September 25, 2020. \\ Address correspondence to \\ Darrell Pilling, Ph.D., or \\ Richard H. Gomer, Ph.D., \\ Department of Biology, Texas \\ A\&M University, 3474 TAMU, \\ College Station, TX 77843- \\ 3474. E-mail: dpilling@bio. \\ tamu.edu orrgomer@tamu.edu.
}

\begin{abstract}
High-fat diet (HFD) -induced inflammation and steatosis of adipose tissue and liver are associated with a variety of serious health risks. Sialic acids are found as the distal terminal sugar on glycoproteins, which are removed by sialidases (neuraminidases). In humans and mice, pulmonary fibrosis is associated with up-regulation of sialidases, and injections of sialidase inhibitors attenuate bleomycininduced pulmonary fibrosis. Sialidase levels are altered in obese rodents and humans. This report shows that for mice on an HFD, injections of the sialidase inhibitor $\mathrm{N}$-acetyl-2,3-dehydro-2-deoxyneuraminic acid inhibit weight gain, reduce steatosis, and decrease adipose tissue and liver inflammation. Compared with control, mice lacking the sialidase neuraminidase 3 have reduced HFD-induced adipose tissue and liver inflammation. These data suggest that sialidases promote adipose and liver inflammation in response to a high-fat diet. (Am J Pathol 2021, 191: 131-143; https://doi.org/10.1016/ j.ajpath.2020.09.011)
\end{abstract}

In the United States, approximately $40 \%$ of adults are obese (body mass index, $\geq 30 \mathrm{~kg} / \mathrm{m}^{2}$ ), leading to an estimated annual medical cost of $\$ 150$ billion and approximately 200,000 deaths. ${ }^{1-3}$ Obesity is one of the most prominent risk factors for many chronic diseases, including type 2 diabetes, cardiovascular disease, and nonalcoholic fatty liver disease. Approximately $25 \%$ of adults in highly industrialized nations have nonalcoholic fatty liver disease, with approximately $5 \%$ of them having nonalcoholic fatty liver disease with liver inflammation (hepatitis), a more serious condition called nonalcoholic steatohepatitis. ${ }^{4-6}$ Up to $40 \%$ of individuals with nonalcoholic steatohepatitis progress to advanced liver fibrosis and eventually cirrhosis.

Obesity is the accumulation of body fat as the result of excessive food intake and/or lack of exercise. Obesity induces adipocyte metabolic dysregulation and the production of inflammatory cytokines, leading to systemic metabolic dysregulation, such as the inability to effectively control systemic glucose levels (insulin resistance), elevated lipid levels (dyslipidemia), and immune cell recruitment to, and activation in, adipose tissue and liver (inflammation). ${ }^{8}$ Excess calories lead to elevated circulating levels of glucose and free fatty acids, which force adipocytes to accumulate more lipid and expand in size, leading to increased oxidative stress in adipocytes and local hypoxia of the tissue, due to the inability of oxygen to diffuse across the tissue. ${ }^{8,9}$ These processes lead to adipocyte cell death, initiating the activation of adipose tissue macrophages. ${ }^{9,10}$ In the liver, excess calories lead to Kupffer cell (hepatic macrophage) activation, which promotes inflammation and increased hepatocyte fatty acid synthesis, leading to hepatic steatosis (abnormal retention of lipids within the hepatocytes) and eventual fibrosis or cirrhosis. ${ }^{8,11}$

Sialic acids are often found as the distal terminal sugar on the oligosaccharide chains of glycoconjugates, such as glycoproteins. Sialidases (alias neuraminidases) are enzymes that remove this sialic acid from glycoconjugates. ${ }^{12}$ Neuraminidase (NEU) 1 to 4 are the four sialidases seen

Supported by NIH HL-132919 and GM118355-03S (R.H.G.)

Disclosures: Texas A\&M University has patent applications on the use of sialidase inhibitors to regulate obesity. D.P., T.R.K., and R.H.G. are inventors on a patent application for the use of sialidase inhibitors as antiinflammatory and anti-obesity compounds. 
in mammals. ${ }^{13} \mathrm{~N}$-acetyl-2,3-dehydro-2-deoxyneuraminic acid (DANA) inhibits mammalian sialidases. ${ }^{14}$ Previous studies have found that injections of DANA or lack of NEU3 both attenuate bleomycin-induced lung fibrosis in mice. ${ }^{15,16}$ The role of sialidases in the regulation of high-fat diet-induced obesity is unclear, with up-regulation or down-regulation of different sialidase proteins in different tissues, suggesting a complex association between obesity and sialidases. ${ }^{17-19}$ Changes in sialidase levels appear to lead to the dysregulation of insulin signaling and glucose metabolism. ${ }^{18,19}$

Because excess calories lead to adipose tissue and liver inflammation, steatosis, and fibrosis, and because injections of DANA and lack of endogenous NEU3 both inhibit bleomycin-induced lung inflammation and fibrosis, this study examined whether injections of DANA and/or endogenous NEU3 could inhibit obesity-induced adipose tissue, liver inflammation, and steatosis in a mouse model.

\section{Materials and Methods}

\section{Mouse Model of Obesity}

All procedures were done with approval of the Texas A\&M University institutional animal care and use committee. The 12- to 16-week-old male C57BL/6 mice (number 000664; Jackson Laboratory, Farmington, CT) were fed standard rodent chow (15\% kcal fat; Teklad 8604; Envigo, Madison WI), and obese C57BL/6 mice (number 380050; Jackson Laboratory) were fed a high-fat diet from 6 weeks of age (60\% kcal fat; D12492 formula; Research Diets, New Brunswick, NJ). The 12-week-old male C57BL/6backcrossed $\mathrm{Neu}^{-/-}$knockout mice $\left(\mathrm{Neu} 3^{-/-}\right)$strain B6.129-NEU3 ${ }^{\text {tm1Yamk }}$ mice ${ }^{20}$ were also fed standard and HFD chow. Mice were placed on the specified diets for 6 weeks before the start of treatment. Mice were randomly assigned to dietary and treatment groups by personnel uninvolved with the study. Mice were housed with a 12-hour/ 12-hour light-dark cycle with free access to food and water. All procedures were performed between $9 \mathrm{Am}$ and noon.

The i.p. injections of phosphate-buffered saline (PBS) or DANA (EMD-Millipore, Burlington, MA) at $10 \mathrm{mg} / \mathrm{kg}$ in PBS were given every 48 hours, as described previously. ${ }^{15}$ For glucose tolerance tests, mice were fasted for 16 hours before i.p. injections of $1.5 \mathrm{~g} / \mathrm{kg}$ glucose (Amresco, Solon, $\mathrm{OH}$ ) in PBS, as described elsewhere. ${ }^{21}$ Blood glucose levels were measured before glucose administration ( 0 minutes), and at 20,40,60, 90, and 120 minutes after the injection using commercial blood glucose test strips (CVS Pharmacy, Woonsocket, RI). Mice were euthanized 35 days after initiation of treatment by asphyxiation with $\mathrm{CO}_{2}$ at $3 \mathrm{~L} /$ minute. $^{22}$

\section{Histology and Antibody Staining}

Following euthanasia, organs, including epididymal white adipose and interscapular brown adipose tissue, liver, spleen, lungs, and kidneys, were weighed before processing. Pieces of adipose tissue and liver were snap frozen in liquid nitrogen and stored at $-80^{\circ} \mathrm{C}$; embedded in OCT compound (VWR, Radnor, PA), frozen, and stored at $-80^{\circ} \mathrm{C}$; or fixed in Zn-buffered formalin solution $(0.1 \%$ $\mathrm{ZnSO}_{4} ; 3.8 \%$ formaldehyde; VWR) for 2 days, and then placed in $10 \%$ and then $30 \%$ sucrose solution in PBS for 2 days each on ice. Fixed tissues were kept in $70 \%$ ethanol at room temperature until paraffin processing and sectioning at $5 \mu \mathrm{m}$.

To determine the amount of steatosis (accumulation of fat in the cells of the liver), OCT-embedded unfixed liver tissue sections were stained with oil red $\mathrm{O}$ to detect the accumulation of lipids, as described elsewhere. ${ }^{23}$ Paraffinembedded tissue sections were stained with hematoxylin and eosin to determine adipocyte size, inflammation, and fibrosis, as described previously. ${ }^{21,24}$

Before antibody staining, fixed tissue sections were deparaffinized, and antigens were retrieved using $10 \mathrm{mmol} / \mathrm{L}$ sodium citrate, $\mathrm{pH} 6.0$, at $98^{\circ} \mathrm{C}$ for 20 minutes, as described earlier. ${ }^{25}$ As previously described, ${ }^{15,21,24}$ sections of adipose and liver tissue were stained with $5 \mu \mathrm{g} / \mathrm{mL}$ antibodies against Mac2 [rat monoclonal antibody (Ab); clone M3/38; BioLegend, San Diego, CA] to detect inflammatory and tissue macrophages, F4/80 (rabbit monoclonal Ab; D2S9R; Cell Signaling Technology, Danvers, MA) to detect tissue resident macrophages, CD64 (rabbit monoclonal Ab; 50086R001; SinoBiological, Wayne, PA) to detect Fc- $\gamma$ receptor 1 expression, C-type lectin domain family 4 member $\mathrm{F}$ (CLEC4F; goat Ab; AF2784; Novus Biologicals, Littleton, $\mathrm{CO}$ ) to specifically detect Kupffer cells, MRP8 (goat Ab; R\&D Systems, Minneapolis, MN) to detect neutrophils and inflammatory macrophages, or mitochondrial uncoupling protein 1 (UCP1; rabbit Ab; GTX112784; Genetex, Irvine, CA) found in brown fat. Some adipose and liver sections were incubated overnight at $4^{\circ} \mathrm{C}$ with $1 \mu \mathrm{g} / \mathrm{mL}$ rabbit polyclonal anti-NEU1 (TA335236; Origene, Rockville, MD), anti-NEU2 (TA324482; Origene), or anti-NEU4 (AP52856PU-N; Origene) in PBS $+2 \%$ bovine serum albumin or NEU3 (TA343356; Origene) in PBS containing $500 \mathrm{mmol} / \mathrm{L} \mathrm{NaCl}, 2 \%$ bovine serum albumin, and $0.1 \% \mathrm{NP}$ 40 alternative (EMD Millipore, Billerica, MA), as described previously. ${ }^{15,16}$ Secondary F(ab') 2 biotin-conjugated donkey anti-rat, anti-goat, or anti-rabbit antibodies were from Jackson ImmunoResearch (West Grove, PA) or Novus Biologicals, and biotinylated antibodies were revealed with streptavidin-conjugated alkaline phosphatase staining (Vector Laboratories, Burlingame, CA). Sections were counterstained with hematoxylin.

\section{Stromal Vesicular Cell Culture}

Stromal vascular fraction (SVF) cell isolation from epididymal white adipose tissue of C57BL/6 mice on the regular diet was performed as described. ${ }^{21,26}$ SVF cells were resuspended at $5 \times 10^{4}$ cells $/ \mathrm{mL}$ in Dulbecco's modified 
Eagle's medium (Lonza, Wakersville, MD), containing 10\% calf serum (Seradigm-VWR), $100 \mathrm{U} / \mathrm{mL}$ penicillin, $100 \mu \mathrm{g} /$ $\mathrm{mL}$ streptomycin, and $2 \mathrm{mmol} / \mathrm{L}$ glutamine (Lonza) at $37^{\circ} \mathrm{C}$ in a humidified $5 \% \mathrm{CO}_{2}$ incubator in 96-well $\mu$-plates (ibidi, Madison, WI). At approximately $80 \%$ confluence, differentiation was induced by incubating cells in Dulbecco's modified Eagle's medium containing serum, antibiotics, 250 $\mathrm{ng} / \mathrm{mL}$ dexamethasone, $500 \mathrm{ng} / \mathrm{mL}$ insulin, and $40 \mu \mathrm{g} / \mathrm{mL} 3-$ isobutyl-1-methylxanthine (all from MilliporeSigma), in the presence or absence of $200 \mu \mathrm{mol} / \mathrm{L}$ DANA. After 4 days, the cells were air dried, fixed, and stained with oil red $\mathrm{O}$ or anti-perilipin antibodies (Novus Biologicals), as described previously. ${ }^{21,27}$

\section{Image Quantification}

Tissue sections stained with antibodies, hematoxylin and eosin, or oil red $\mathrm{O}$ were imaged with a Nikon Eclipse Ti2 microscope (Nikon Instruments, Melville, NY) and analyzed with ImageJ2 software Fiji version $1.53 \mathrm{~d}$ (NIH, Bethesda, MD; https://imagej.net/Welcome, last accessed August 30, 2020). ${ }^{28}$ The percentage area of stained tissue was quantified as a percentage of the total area of the tissue, as described previously. ${ }^{15,21,24,29}$ Adipocyte size was calculated using the ImageJ plug-in Adiposoft version 1.16 (Imaging Unit of the Center for Applied Medical Research, University of Navarra, Pamplona, Spain). ${ }^{30}$

\section{Cytokine and Serum Protein Quantification}

After mice were euthanized, blood was collected from the abdominal aorta and chilled on ice. After 30 minutes, the blood was clarified by centrifugation at $10,000 \times g$ for 5 minutes at $4^{\circ} \mathrm{C}$ to isolate serum, which was then stored at $-80^{\circ} \mathrm{C}$. Serum cytokines were measured with a 13-plex LEGENDplex Mouse Inflammation Panel kit (BioLegend) following the manufacturer's instructions using an Accuri C6 flow cytometer (Accuri C6; BD Biosciences, San Jose, CA). Data were analyzed using LEGENDplex data analysis software version 8.0 (BioLegend), and the concentration of proteins was calculated from standard curves. Alanine transaminase (ALT) and aspartate aminotransferase (AST) levels were measured by enzyme activity assays (Cayman Chemical, Ann Arbor, MI), following the manufacturer's instructions.

\section{Statistical Analysis}

Statistical analysis was performed using Prism software version 7.05 (GraphPad Software, La Jolla, CA). Statistical significance between two groups was determined by $t$-test, or between multiple groups using analysis of variance with the Sidak test post-test, and significance was defined as $P<0.05$.

\section{Results}

DANA, but Not Loss of NEU3, Reduces High-Fat Diet-Induced Increases in Body and Organ Weights

Obesity is linked with inflammation in adipose tissue and liver. ${ }^{8,31}$ Previous research has found that injections of DANA inhibit bleomycin-induced lung inflammation and fibrosis, ${ }^{15}$ which is reduced in Neu3 knockout mice $\left(\mathrm{Neu3}^{-/-}\right){ }^{16}$ To determine if DANA can inhibit HFDinduced weight gain, adipose tissue or liver inflammation, or steatosis, mice on an HFD were treated with or without injections of DANA. Compared with C57BL/6 mice on a regular diet, C57BL/6 mice on the HFD had significant weight gain (Figure 1A). Mice fed regular chow and treated with either PBS or DANA injections, on the other hand, had no significant differences in weight (Figure 1A). In the C57BL/6 HFD-fed mice, compared with the PBS-injected mice, there was a significant reduction in weight gain observed in mice treated with DANA injections starting at 21 days of DANA treatment (Figure 1A). To determine whether DANA could prevent HFD-induced increases in organ weights, mice were euthanized and epididymal white adipose and interscapular brown adipose tissue, liver, spleen, lungs, and kidneys were weighed at day 35. Mice fed regular rodent chow and treated with either DANA or PBS injections had no significant differences in any organ weights (Figure 1C and Supplemental Figure S1). As a percentage of body weight, HFD-fed mice had higher white and brown adipose tissue weights compared with mice on regular chow. HFD-fed mice treated with DANA injections had lower white fat and brown fat weights compared with control HFD-fed mice (Figure 1C). As a percentage of body weight, C57BL/6 mice on the HFD had lower liver weights compared with mice on regular chow, although the actual liver weights were slightly higher in HFD-fed mice (means \pm SEM, $1.97 \pm 0.2 \mathrm{~g} ; n=5$ ), compared with those fed on regular chow $(1.75 \pm 0.07 \mathrm{~g} ; n=5)$. HFD-fed mice treated with DANA had higher liver weights compared with control HFD-fed mice (Figure 1C).

There was no significant difference in HFD-induced weight gain between $\mathrm{C} 57 \mathrm{BL} / 6$ and $\mathrm{Neu}^{-/-}$mice (Figure 1B), suggesting that there appears to be no general inability of $\mathrm{Neu}^{-/-}$mice to process food and increase weight. Compared with $\mathrm{Neu}^{-/-}$mice fed regular rodent chow, HFD-fed $\mathrm{Neu}^{-/-}$mice had higher white and brown fat weights, and lower liver tissue weights. Compared with C57BL/6 mice, Neu $3^{-/}$mice fed regular chow had significantly higher liver weights. There was no significant difference in adipose or liver weights between C57BL/6 and $\mathrm{Neu}^{-/-}$mice fed HFD (Figure 1C). These data indicate that injections of DANA can modulate organ weights in diet-induced obesity. However, NEU3 may not be involved with HFD-induced weight gain, and the effects of DANA on body and organ weights may not be due to DANA inhibiting NEU3. 

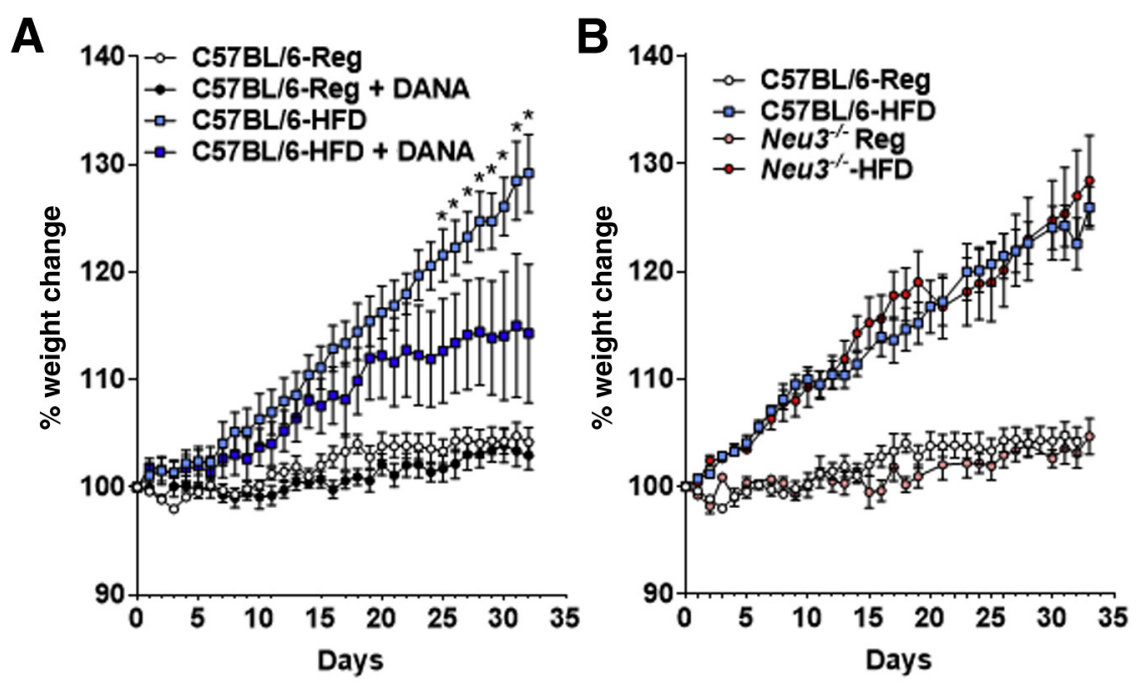

Figure $1 \mathrm{~N}$-acetyl-2,3-dehydro-2-deoxyneuraminic acid (DANA)-treated mice are resistant to high-fat diet (HFD) -induced increases in total body and organ weight. $\mathrm{C} 57 \mathrm{BL} / 6$ or $\mathrm{Neu}^{-/-}$mice were maintained on regular diet (Reg) or HFD for 6 weeks before the start of treatment. Mice were injected every 48 hours with phosphate-buffered saline or DANA for 35 days. A and B: Graphs show body weights of C57BL/6 (A) and Neu3 ${ }^{-1-}$ (B) mice. C: Epididymal white fat, brown fat, and liver weights. Data are expressed as means \pm SEM. $n=3$ to 6 mice per group. ${ }^{*} P<0.05$ comparing $\mathrm{C} 57 \mathrm{BL} / 6$ mice on HFD and mice on HFD and injected with DANA at each day, significant from day 24 through day 33 ( $t$-test); ${ }^{\dagger} P<0.05,{ }^{\dagger \dagger} P<0.01$, and ${ }^{\dagger \dagger \dagger} P<0.001$ (one-way analysis of variance, Sidak test).

DANA, but Not Loss of NEU3, Attenuates an HFDInduced Increase in Glucose Levels after Glucose Injection

Obesity leads to systemic metabolic dysregulation and type 2 diabetes, with an inability to effectively regulate systemic glucose levels. ${ }^{8,32}$ As seen previously, ${ }^{33,34}$ compared with C57BL/6 mice on a regular diet, HFD-fed mice had a significant increase in basal glucose levels (Figure 2A). Mice fed standard rodent chow and treated with either DANA or PBS injections had no significant differences in fasting glucose levels (time $=0$ minutes) or glucose levels after the glucose injection (Figure 2A). HFD-fed mice injected with DANA had significantly lower blood glucose levels at 60 minutes compared with control HFD-fed mice (Figure 2A), and using area under the curve analysis, HFD-fed mice treated with DANA had significantly lower total glucose levels compared with the HFD-fed control group (Figure 2C).

$\mathrm{Neu}^{-/-}$mice on regular diet had similar fasting glucose levels to C57BL/6 mice (Figure 2B). Compared with $\mathrm{Neu}^{-/-}$mice on a regular diet, HFD-fed $\mathrm{Neu} 3^{-/-}$mice had a significant increase in glucose levels, both at time $=0$ and after the glucose injection (Figure 2, B and C). There was no difference in blood glucose levels following glucose injection between $\mathrm{C} 57 \mathrm{BL} / 6$ and $\mathrm{Neu}^{-/-}$mice on regular or HFD (Figure 2, B and C). The results suggest that DANA injections may have some ability to regulate glucose levels in obesity, and that this may be due to a NEU3-independent process.

DANA or Loss of NEU3 Decreases Crown-Like Structures in White Adipose Tissue in Mice on an HFD

Obesity leads to an increase in adipocyte size (hypertrophy) and/or an increase in adipocyte numbers (hyperplasia). ${ }^{34,35}$ Compared with adipocytes in the white adipose tissue from $\mathrm{C} 57 \mathrm{BL} / 6$ and $\mathrm{Neu}^{-/-}$mice on the regular diet (Figure 3, A, E and G, and Supplemental Figure S2), adipocytes in $\mathrm{C} 57 \mathrm{BL} / 6$ and $\mathrm{Neu} 3^{-/-}$mice on the HFD were larger (Figure 3, C, F, and G, and Supplemental Figure S2). Compared with HFD buffer-treated mice, DANA-treated C57BL/6 mice had a significant reduction in adipocyte size (Figure 3, A-D and G, and Supplemental Figure S2). 

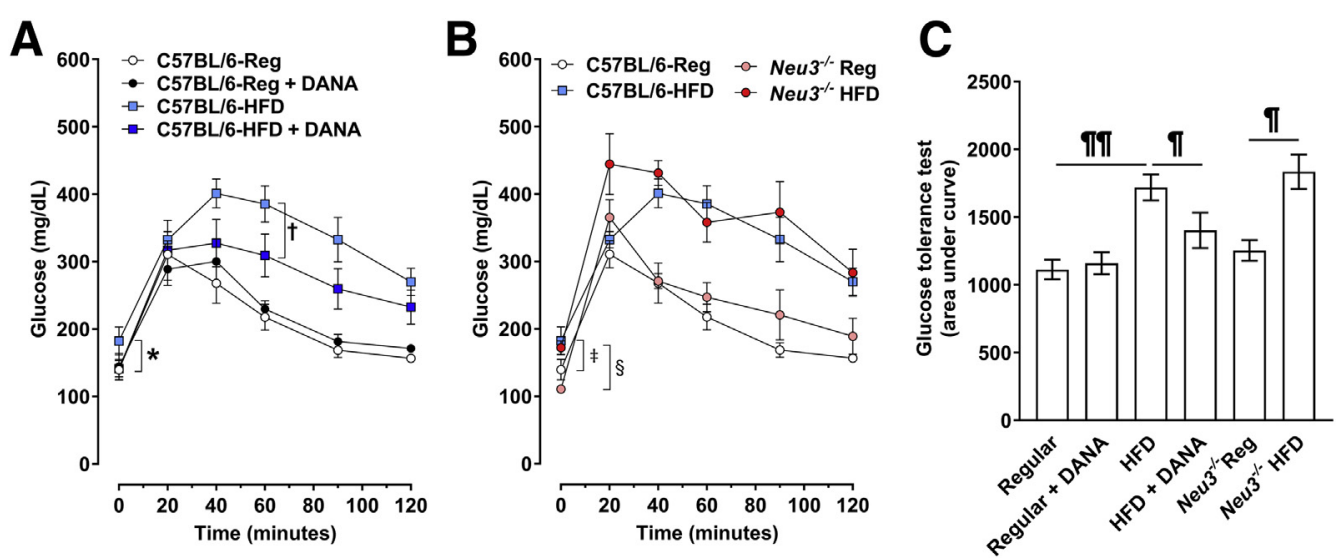

Figure $2 \mathrm{~N}$-acetyl-2,3-dehydro-2-deoxyneuraminic acid (DANA)-treated mice have improved glucose tolerance. A and B: C57BL/6 mice on regular diet (Reg) or high-fat diet (HFD) for 6 weeks before the start of treatment. Mice were injected every 48 hours with phosphate-buffered saline or DANA. Neu3 ${ }^{-/-}$mice on Reg or HFD did not receive injections. At 35 days, mice were fasted overnight and then received an i.p. injection of glucose (1.5 g/ $/ \mathrm{gg}$ body weight), and tail vein blood samples were assessed for glucose at the indicated times. C: Glucose tolerance over 120 minutes was assessed by area under the curve analysis. Data are expressed as means \pm SEM. ${ }^{*} P<0.05$ comparing mice on Reg and HFD ( $t$-test) $;^{\dagger} P<0.05$ comparing mice on HFD and HFD + DANA ( $t$-test); ${ }^{\ddagger} P<0.05$ comparing mice on Reg

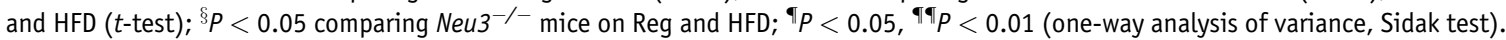

There was no significant difference in adipocyte size between C57BL/6 and $\mathrm{Neu}^{-/-}$mice fed regular or HFD (Figure 3G and Supplemental Figure S2). These data suggest that injections of DANA, but not disruption of Neu3, can decrease white adipose tissue adipocyte cell size in mice on an HFD.

Although adipose tissue from nonobese mammals contains a variety of tissue-resident immune cells, the accumulation of inflammatory cells in obesity may contribute to both local adipocyte tissue dysfunction and drive systemic inflammation. ${ }^{8,33}$ To determine if DANA and/or NEU3 could regulate the number or composition of adipose tissue immune cells, the current study assessed cells in tissue sections. Mac2-positive macrophages that aggregate into crown-like structures (CLSs) are thought to scavenge lipid droplets and dead adipocytes, and the number of
C57BL/6 Reg C57BL/6 Reg + DANA C57BL/6 HFD
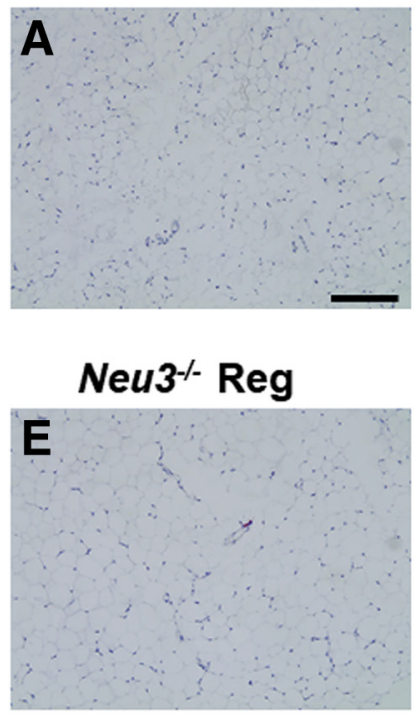

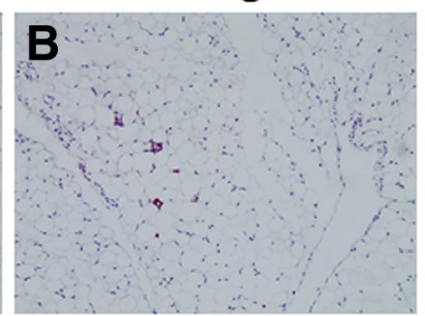

Neu3-- Reg HFD

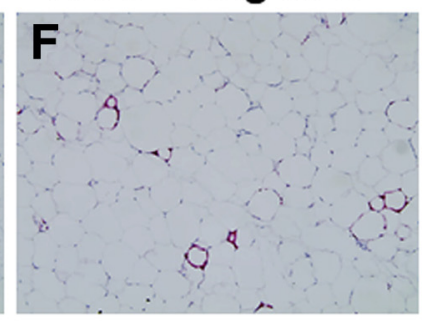

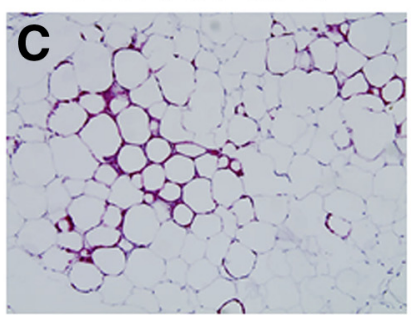

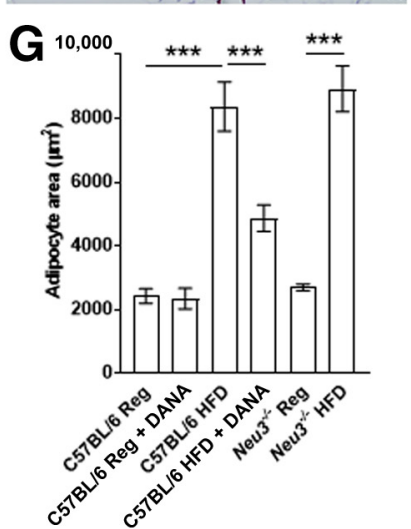

C57BL/6 HFD + DANA


Figure $3 \mathrm{~N}$-acetyl-2,3-dehydro-2-deoxyneuraminic acid (DANA) injections and loss of neuraminidase 3 (NEU3) reduce high-fat diet (HFD)-induced

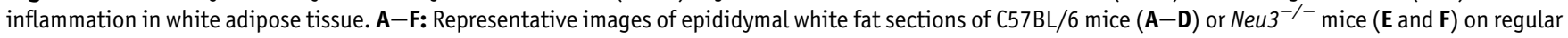
$\operatorname{diet}(\operatorname{Reg} ; \mathbf{A}$ and $\mathbf{E}), \operatorname{Reg}+\mathrm{DANA}(\mathbf{B}), \mathrm{HFD}(\mathbf{C}$ and $\mathbf{F})$, or HFD + DANA (D) were stained with anti-Mac2 antibodies. Images are representative of three to eight mice per condition. G: Average adipocyte area was calculated. H: Mac2-positive crown-like structures (CLSs) were counted. Data are expressed as means \pm SEM (G and $\mathbf{H})$. $n=3$ to 8 mice per group ( $\mathbf{G}$ and $\mathbf{H}) .{ }^{*} P<0.05,{ }^{* *} P<0.001$ (one-way analysis of variance, Sidak test). Scale bar $=0.2 \mathrm{~mm}(\mathbf{A}-\mathbf{F})$. 
CLSs correlates with systemic insulin resistance in obese patients. ${ }^{31,36,37}$ Compared with mice on a regular diet, both C57BL/6 and $\mathrm{Neu}^{-1-}$ mice on an HFD had a significant increase in the number of Mac2-positive CLSs (Figure 3, A, C, E, F, and H, and Supplemental Figure S3). Compared with buffer-treated HFD C57BL/6 mice, DANA-treated HFD C57BL/6 mice had a significant reduction in the number of Mac2-positive CLSs (Figure 3, C, D, and H, and Supplemental Figure S3). There was no difference in the number of Mac2-positive CLSs between C57BL/6 mice and $\mathrm{Neu}^{-/-}$mice on the regular diet (Figure 3, A, E, and H, and Supplemental Figure S3). Compared with C57BL/6 mice on the HFD, the number of Mac2-positive CLSs was significantly lower in HFD-fed $\mathrm{Neu}^{-1-}$ mice (Figure 3, C, F, and H, and Supplemental Figure S3). These data suggest that injections of DANA or loss of NEU3 decreases macrophage accumulation in white adipose tissue in mice on an HFD.

\section{DANA or Loss of NEU3 Decreases Adipose Tissue Macrophages in Mice on an HFD}

Macrophages are the most abundant immune cells in the adipose tissue of humans and mice, and the composition of macrophage populations changes with obesity. ${ }^{8,33}$ Tissueresident adipose macrophages express CD64 and F4/80, whereas inflammatory macrophages express a variety of markers, including Mac2. ${ }^{38-41}$ As observed previously for C57BL/6 mice, ${ }^{40,42,43}$ compared with normal-diet mice, both $\mathrm{C} 57 \mathrm{BL} / 6$ and $\mathrm{Neu}^{-1-}$ mice on an HFD had increased numbers of F4/80- and Mac2-positive cells in the adipose tissue, and treatment with DANA significantly reduced these numbers in C57BL/6 mice (Figure 4 and Supplemental Figure S3). For mice on either regular diet or HFD, there were fewer CD64-, F4/80-, and Mac2-positive cells in $\mathrm{Neu}^{-/-}$mice compared with $\mathrm{C} 57 \mathrm{BL} / 6$ mice

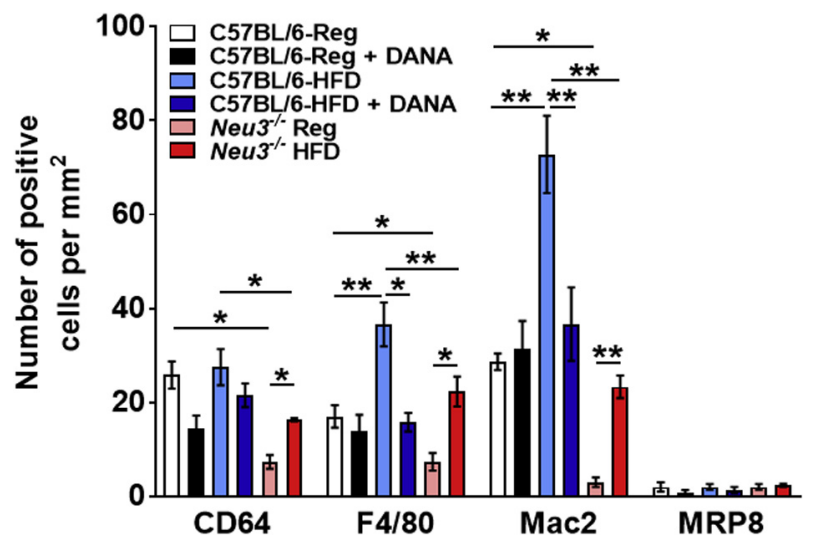

Figure $4 \mathrm{~N}$-acetyl-2,3-dehydro-2-deoxyneuraminic acid (DANA) injections or loss of neuraminidase 3 (NEU3) reduces high-fat diet (HFD)induced changes in adipose tissue macrophages. Sections of epididymal white adipose tissue were stained with antibodies for the indicated markers. Data are expressed as means \pm SEM. $n=3$ to 8 mice per group. ${ }^{*} P<0.05$, ${ }^{* *} P<0.01$ (one-way analysis of variance, Sidak test). Reg, regular diet.
(Figure 4 and Supplemental Figure S3). To determine if the increase in the number of F4/80- and Mac2-positive cells was indicative of a general inflammatory response, adipose tissues were stained with anti-MRP8 antibodies to detect neutrophils. ${ }^{44}$ There were few MRP8-positive cells in white adipose tissue, and no differences were detected in the number of MRP8-positive cells in either C57BL/6 or $\mathrm{Neu} 3^{-1-}$ mice on regular or HFD (Figure 4 and Supplemental Figure S3). These data suggest that HFDinduced increases in white adipose tissue macrophage numbers can be attenuated by injections of DANA, and that loss of NEU3 decreases some HFD-induced inflammation.

\section{DANA Inhibits Adipocyte Differentiation}

To determine if DANA can directly regulate adipocyte differentiation, SVF cells were differentiated from regular diet C57BL/6 mice in vitro in the presence or absence of DANA, and cells were stained for neutral lipids with oil red $\mathrm{O}$, and for the lipid droplet protein perilipin. ${ }^{45}$ Differentiated SVF cells showed positive perilipin and oil red $\mathrm{O}$ staining (Figure 5, A, B, and D). Significant inhibition of oil red $\mathrm{O}$-positive SVF cells was observed with increasing concentrations of DANA (Figure 5C). Compared with control differentiated SVF cells, SVF cells differentiated in the presence of DANA had reduced percentages of perilipinpositive cells (Figure 5D). Undifferentiated SVF cells cultured in the presence or absence of DANA had no detectable perilipin staining (Figure 5D). These data suggest that DANA can inhibit adipocyte differentiation.

\section{DANA or Loss of NEU3 Attenuates HFD-Induced Changes in Brown Fat UCP1 Expression}

High-fat diet-induced obesity also leads to changes in brown adipose tissue. ${ }^{8,35}$ As previously observed, ${ }^{46}$ compared with C57BL/6 mice on a regular diet, the brown fat of HFD-fed C57BL/6 mice had a reduced percentage of the brown fat tissue staining for nonfat cytoplasm with hematoxylin and eosin (Figure 6G and Supplemental Figure S4, A and C), also observed in $\mathrm{Neu}^{-/-}$mice (Figure 6G and Supplemental Figure S4, E and F). Compared with C57BL/6 HFD-fed mice, mice treated with DANA had a higher percentage of the brown fat tissue staining for nonfat cytoplasm with hematoxylin and eosin (Figure 6G and Supplemental Figure S4, A-D). Brown fat can process lipids and carbohydrate to generate UCP1mediated heat (adaptive thermogenesis). ${ }^{47,48}$ Compared with control diet-fed mice, there was reduced UCP1 staining of brown fat in HFD-fed C57BL/6 mice, which was reversed by DANA (Figure 6, A-D and $\mathrm{H}$ ). Although the brown fat of $\mathrm{Neu}^{-/-}$mice on the HFD had a reduced percentage of the brown fat tissue staining for nonfat cytoplasm with hematoxylin and eosin compared with $\mathrm{Neu} 3^{-/-}$mice on the regular diet, there was no reduction in the UCP1 staining in the tissue (Figure 6, E, F, and H). In 

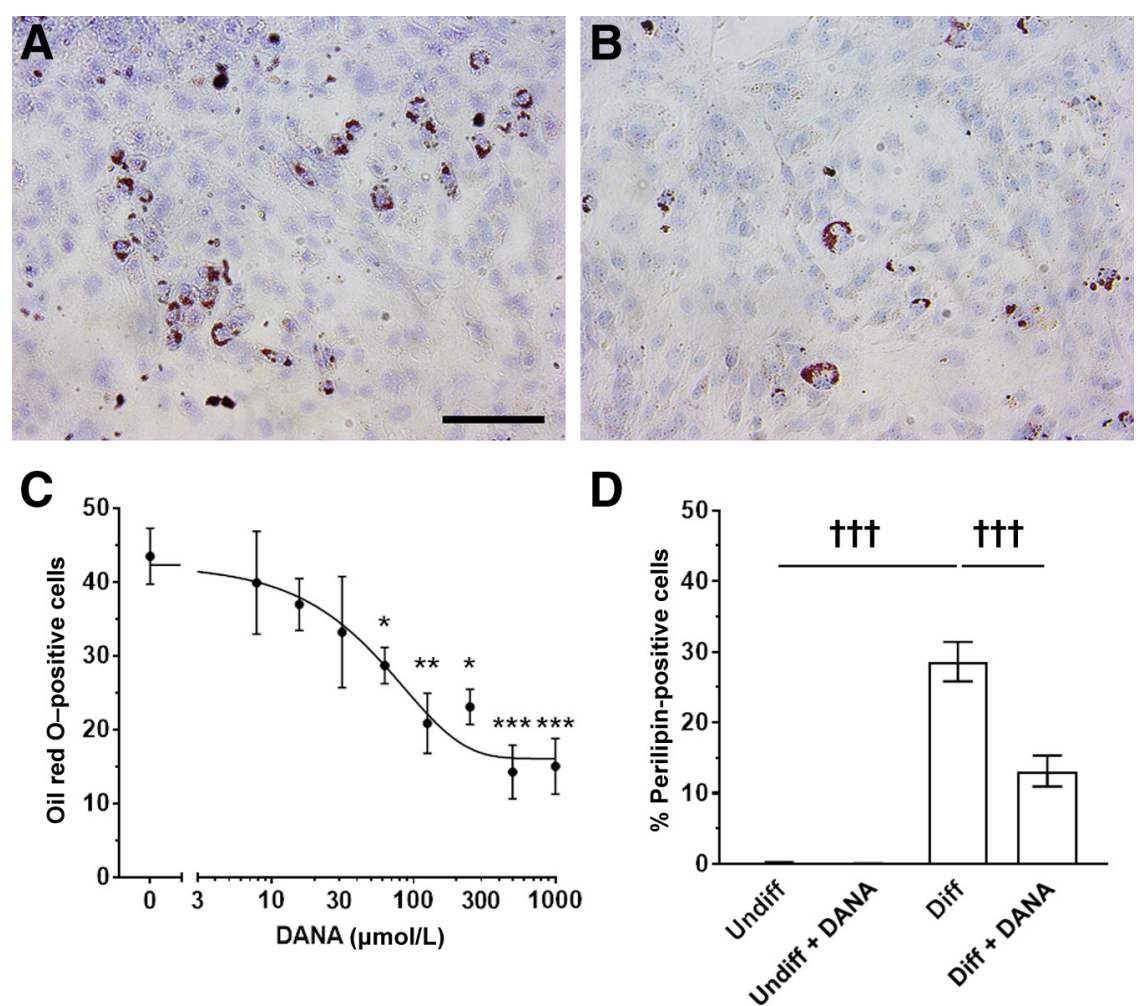

Figure $5 \mathrm{~N}$-acetyl-2,3-dehydro-2-deoxyneuraminic acid (DANA) inhibits adipocyte differentiation. A and B: Stromal vesicular fraction (SVF) cells isolated from $\mathrm{C} 57 \mathrm{BL} / 6$ mice on a regular diet were differentiated in the absence $(\mathbf{A})$ or presence (B) of DANA and were stained with oil red 0 . Images are representative of three mice per condition. C: Quantification of oil red 0-positive cells. D: Cells were stained with antiperilipin antibodies, and the percentage of cells stained was counted. $\mathbf{C}$ and $\mathbf{D}$ : Cells from three mice per group. Data are expressed as means $\pm \mathrm{SEM}(\mathbf{C}$ and $\mathbf{D})$. ${ }^{*} P<0.05,{ }^{*} P<0.01$, and ${ }^{* *} P<0.001$ comparing SVF cells in the presence or absence of DANA ( $t$-test) ${ }^{i \dagger \dagger} P<0.001$ comparing percentage of cells stained (one-way analysis of variance, Sidak test). Scale bar $=0.1$ $\mathrm{mm}$ (A and $\mathbf{B})$. Diff, differentiated; Undiff, undifferentiated. addition, compared with C57BL/6 mice on the HFD, $\mathrm{Neu}^{-1-}$ mice on the HFD had significantly more UCP1 staining (Figure $6 \mathrm{H}$ ). These data suggest that the accumulation of lipid in the brown fat adipocytes and UCP1 protein levels are independently controlled, with DANA but not loss of NEU3 reducing lipid accumulation and NEU3 regulating UCP1 levels.

\section{DANA and NEU3 Reduce HFD-Induced Changes in Liver Inflammation and Steatosis}

Obesity is associated with nonalcoholic fatty liver disease, a spectrum of liver diseases that ranges from simple steatosis (accumulation of fat droplets within the hepatocytes), to hepatitis (inflammation) resulting in nonalcoholic steatosis, and ultimately cirrhosis (fibrosis) and liver failure. ${ }^{49,50}$ Obesity is also associated with liver inflammation, especially increase in macrophages. ${ }^{8,51,52}$ As observed previously, ${ }^{8,42}$ compared with regular-diet mice, C57BL/6 mice on HFD had increased numbers of CD64-, F4/80-, and Mac2-positive cells in the liver (Figure 7, A-C, and Supplemental Figure S5). Injections of DANA reduced the numbers of F4/80- but not CD64- or Mac2positive cells in C57BL/6 mice fed an HFD (Figure 7, A-C, and Supplemental Figure S5). There were fewer CD64- and Mac2-positive cells in Neu $3^{-/-}$mice compared with C57BL/6 mice maintained on either regular or HFD (Figure 7, A and C, and Supplemental Figure S5).
Compared with C57BL/6 mice, $\mathrm{Neu} 3^{-/-}$mice on a regular diet had similar numbers of F4/80-positive cells, but on an

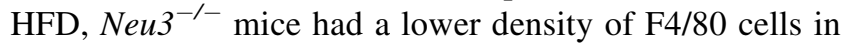
the liver (Figure 7B and Supplemental Figure S5). The number of Mac2-positive cell clusters was significantly

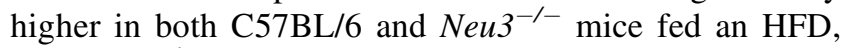
but $\mathrm{Neu} 3^{-/-}$mice had fewer Mac2 cell clusters than C57BL/6 mice (Figure 7D and Supplemental Figure S5). No differences were detected in the total number of CLEC4f-positive Kupffer cells ${ }^{53-55}$ or MRP8-positive neutrophils between $\mathrm{C} 57 \mathrm{BL} / 6$ and $\mathrm{Neu}^{-1-}$ mice, or mice fed regular or HFD (Figure 7, E and F, and Supplemental Figure S5). These data suggest that HFDinduced increases in liver macrophage numbers are attenuated by loss of NEU3 and attenuated for F4/80 macrophages by injections of DANA.

For both C57BL/6 and $\mathrm{Neu}^{-/-}$mice, compared with mice on the regular diet, mice on the HFD had increased steatosis, increased serum ALT and AST levels, and accumulation of oil red O staining (Figure 8, A, B, E, and F, and Supplemental Figure S6, A-E). Compared with C57BL/6 mice, there were no significant differences between steatosis, accumulation of oil red O staining, or AST levels, but ALT levels were higher in $\mathrm{Neu}^{-/-}$mice (Figure 8 and Supplemental Figure S6). Compared with HFD-fed control mice, DANA-treated C57BL/6 mice had reduced steatosis and serum ALT and AST levels (Figure 8, C, D, and G, and Supplemental Figure S6, F and G). These data suggest that 
C57BL/6 Reg
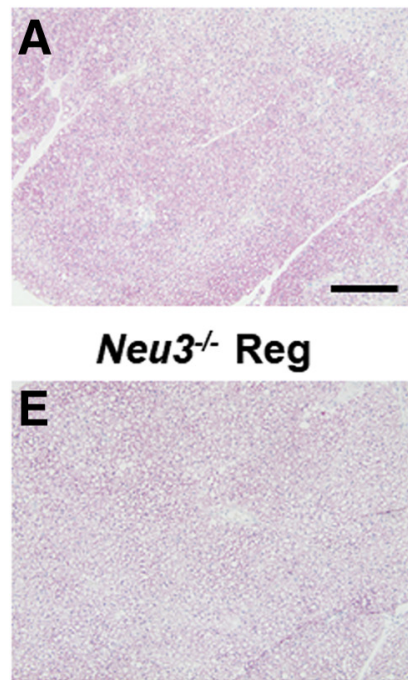

C57BL/6 Reg + DANA

B
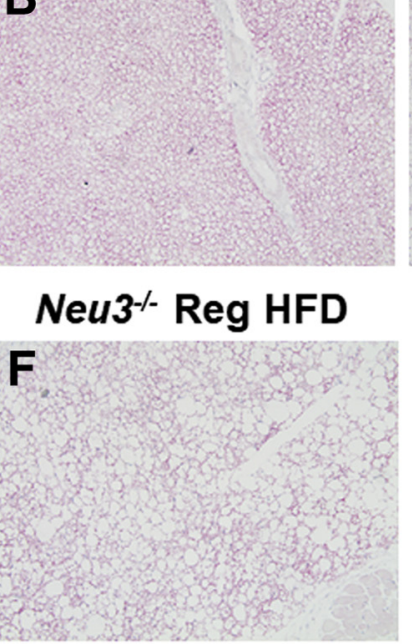

C57BL/6 HFD
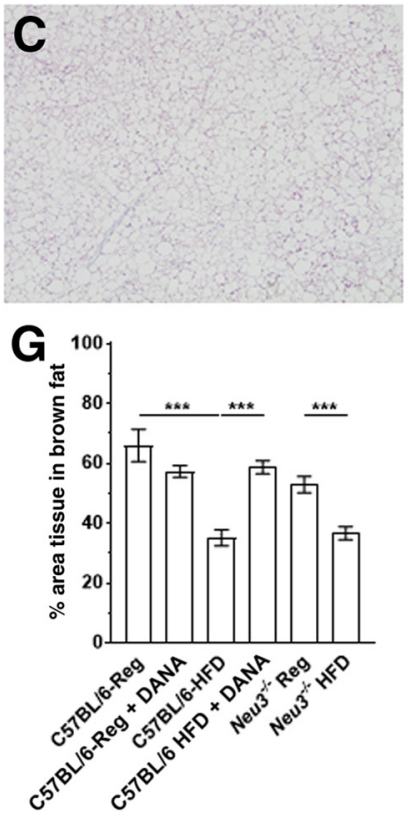

C57BL/6 HFD + DANA
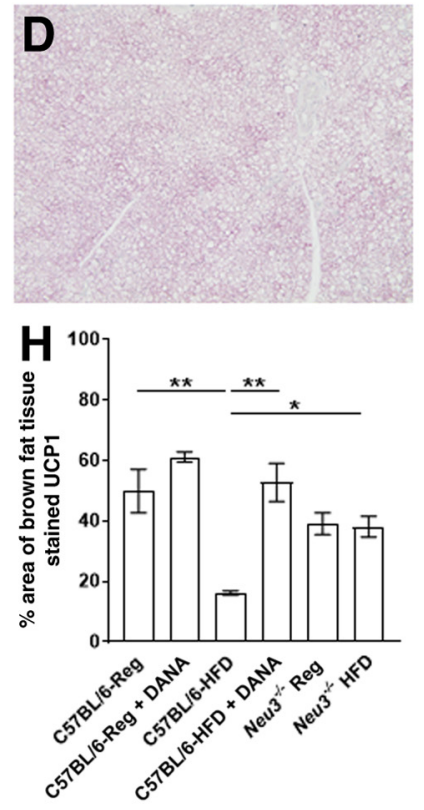

Figure $6 \mathrm{~N}$-acetyl-2,3-dehydro-2-deoxyneuraminic acid (DANA) reduces high-fat diet (HFD)-induced changes in brown adipose tissue. A-F: C57BL/6 $(\mathbf{A}-\mathbf{D})$ and $\mathrm{Neu}^{-/-}$(E and $\left.\mathbf{F}\right)$ mice on regular diet (Reg; $\mathbf{A}$ and $\left.\mathbf{E}\right), \mathrm{HFD}(\mathbf{C}$ and $\mathbf{F})$, Reg + DANA (B), or HFD + DANA (D). A-F: Representative images of brown fat sections were stained with anti-uncoupling protein 1 (UCP1) antibodies. Images are representative of three to seven mice per condition. G: Quantification of percentage tissue area that is not fat. $\mathbf{H}$ : Percentage tissue area stained with anti-UCP1 antibodies. Data are expressed as means \pm SEM (G and $\mathbf{H}) . n=3$ to 7 mice per group $(\mathbf{G}$ and $\mathbf{H})$. ${ }^{*} P<0.05,{ }^{* *} P<0.01$, and ${ }^{* * *} P<0.001$ (one-way analysis of variance, Sidak test). Scale bar $=0.2 \mathrm{~mm}(\mathbf{A}-\mathbf{F})$.

DANA, but not loss of NEU3, can reverse some of the effects of high-fat diet on liver steatosis.

Diet-induced obesity leads to the production of inflammatory cytokines by adipose tissue macrophages, dendritic cells, and $\mathrm{T}$ cells. ${ }^{8}$ As expected, ${ }^{8}$ C57BL/6 mice fed an HFD had elevated serum levels of tumor necrosis factor- $\alpha$ (Supplemental Figure S7). Compared

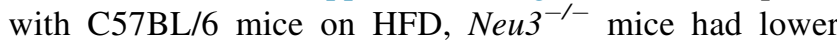
serum levels of IL-6, IL-23, tumor necrosis factor- $\alpha$, and monocyte chemoattractant protein 1, and compared with

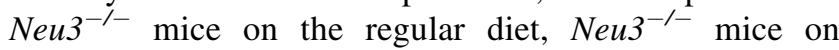
HFD had reduced IL-23 (Supplemental Figure S7). DANA reduced serum levels of IL-17A (Supplemental Figure S7). These data suggest that DANA and NEU3 can affect some systemic cytokines associated with dietinduced obesity.

\section{Sialidase Expression in Adipose and Liver Tissue}

The role of sialidases in the regulation of HFD-induced obesity is unclear, with up-regulation or down-regulation of different sialidase proteins in different tissues, suggesting a complex association between obesity and sialidases. ${ }^{17-19}$ To determine the expression of sialidases, adipose and liver sections were stained with antibodies against the four sialidases. The antibodies were made against domains of the sialidases that are different from each other, do not bind the other sialidases, and stain bands of the expected molecular weights on Western blots of whole cell lysates and lung fluid. ${ }^{15,16}$ As testicular tissue and blood vessels express sialidases, ${ }^{56,57}$ sections of white fat containing testicular tissue or blood vessels, or brown fat with adjacent white fat were stained to further validate these antibodies and to show the differential expression of sialidases between these tissues (Supplemental Figure S8). Staining for NEU1, NEU2, and NEU3 was observed in both testicular tissue and blood vessels, and staining was more pronounced in brown fat than in white fat (Supplemental Figure S8). NEU4 is expressed predominantly in neuronal tissue, ${ }^{58}$ and weak NEU4 staining was observed in all tissues tested (Supplemental Figure S8). For both white and brown fat, the staining of all four sialidases was not significantly different between regular and HFD-fed C57BL/6 mice, but DANA injections reduced staining for NEU3 in adipose tissue in mice on regular diet (Figure 9, A and B, and Supplemental Figures S9 and S10). There were no significant differences in the staining for NEU1 between C57BL/6 and Neu3 ${ }^{-/-}$ mice on the regular or high-fat diet (Figure 9, A and B, and Supplemental Figures S9 and S10). Compared with C57BL/ 6 mice, NEU2 and NEU4 staining in white fat was reduced in $\mathrm{Neu} 3^{-/-}$mice fed either regular or HFD, and NEU2 and NEU4 staining in brown fat was reduced in HFD fed $\mathrm{Neu}^{-/-}$mice (Figure 9, A and B, and Supplemental Figures S9 and S10). In the liver, DANA increased NEU1 

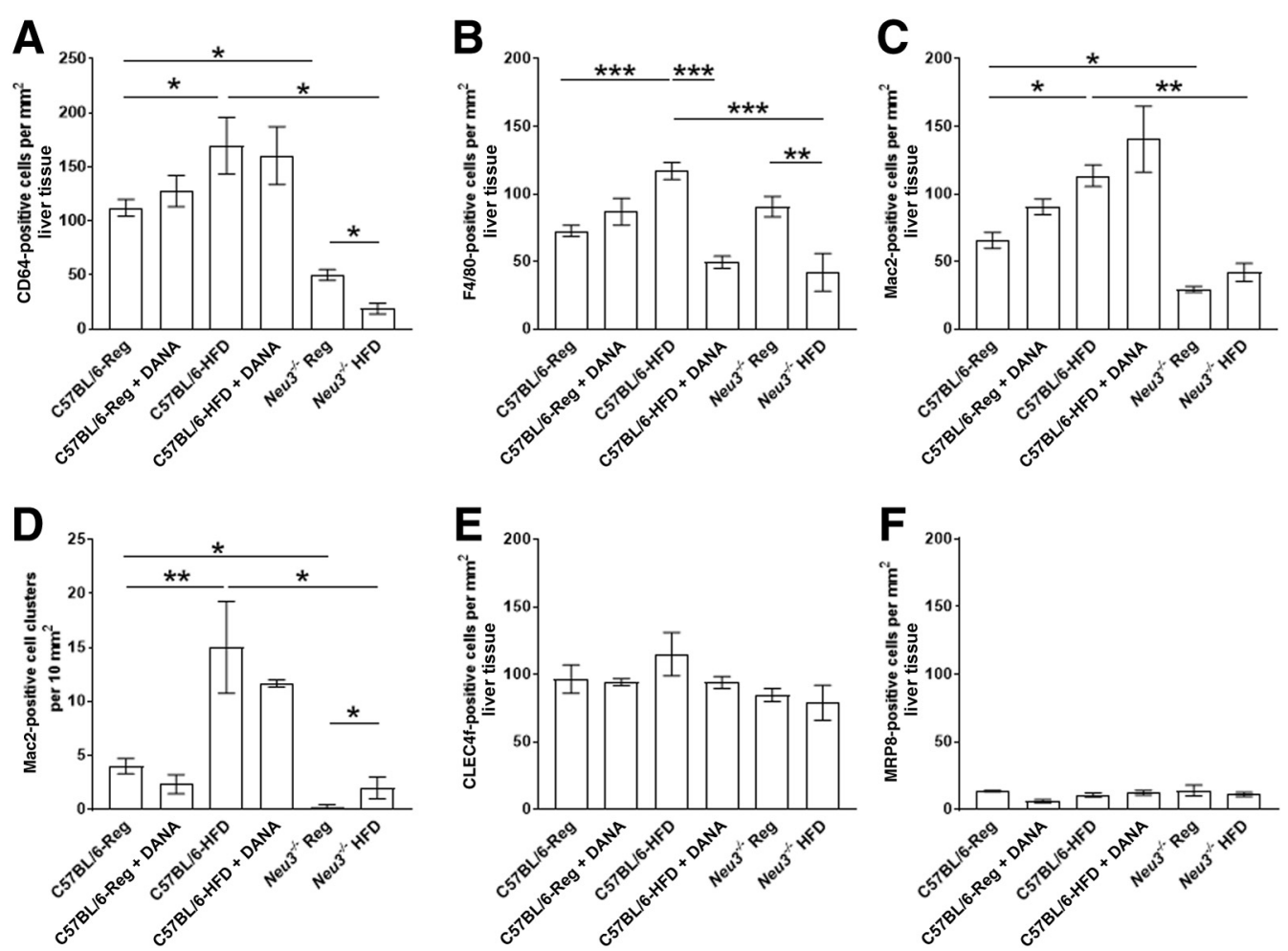

Figure 7 N-acetyl-2,3-dehydro-2-deoxyneuraminic acid (DANA) injections or loss of NEU, neuraminidase 3 (NEU3) reduces high-fat diet (HFD)-induced changes in liver macrophages. Sections of liver tissue were stained with antibodies for CD64 (A), F4/80 (B), Mac2 (C), Mac2 cell clusters (D), C-type lectin domain family 4 member $\mathrm{F}(\mathrm{CLEC}$ f; $\mathrm{E})$, and MRP8 (F). Data are expressed as means \pm SEM. $n=3$ to 8 mice per group. ${ }^{*} P<0.05, * * P<0.01$, and ${ }^{* * * P} P 0.001$ (one-way analysis of variance, Sidak test). Reg, regular diet.

and NEU3 staining in C57BL/6 mice, and reduced NEU3 staining in HFD-fed mice (Figure 9C and Supplemental Figure S11). Staining for NEU1, NEU2, and NEU4 was almost undetectable in liver tissue from $\mathrm{Neu}^{-/-}$mice
(Figure 9C and Supplemental Figure S11). These data suggest that DANA can reverse some of the effects of highfat diet independently of sialidase levels in the adipose and liver tissues.
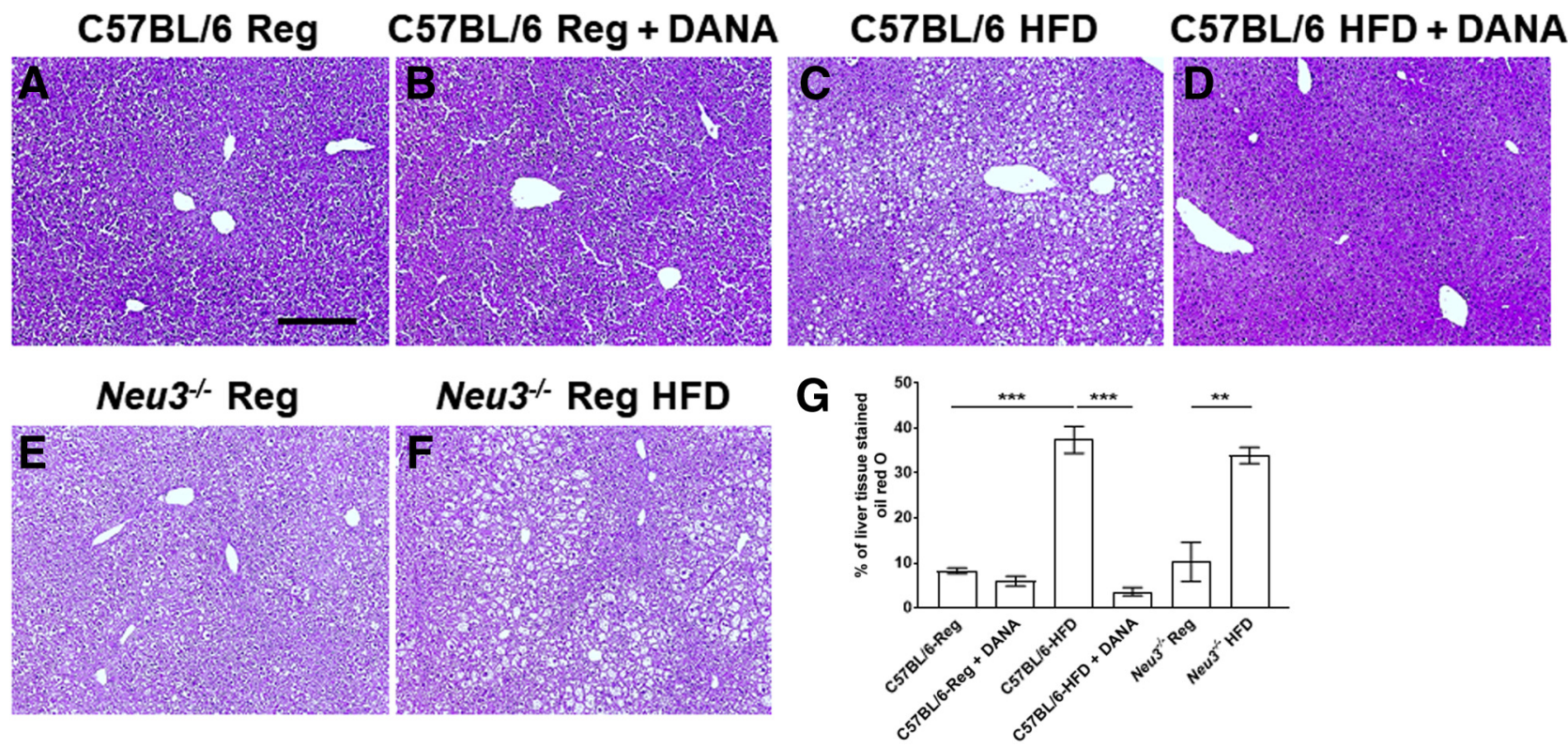

Figure $8 \mathrm{~N}$-acetyl-2,3-dehydro-2-deoxyneuraminic acid (DANA) injections reduce high-fat diet (HFD)-induced changes in liver steatosis. A-F: C57BL/6 $(\mathbf{A}-\mathbf{D})$ and $\mathrm{Neu}^{-1-}$ (E and $\left.\mathbf{F}\right)$ mice on regular diet (Reg; $\mathbf{A}$ and $\left.\mathbf{E}\right), \operatorname{Reg}+\operatorname{DANA}(\mathbf{B}), \mathrm{HFD}(\mathbf{C}$ and $\mathbf{F})$, and HFD + DANA (D). Images show representative liver sections stained with hematoxylin and eosin. G: Quantification of liver sections stained with oil red 0 stain. Data are expressed as means \pm SEM (G). $n=3$ to 8 mice per group $(\mathbf{G}) .{ }^{* *} P<0.01,{ }^{* *} P<0.001$ (one-way analysis of variance, Sidak test). Scale bar $=0.2 \mathrm{~mm}(\mathbf{A}-\mathbf{F})$. 

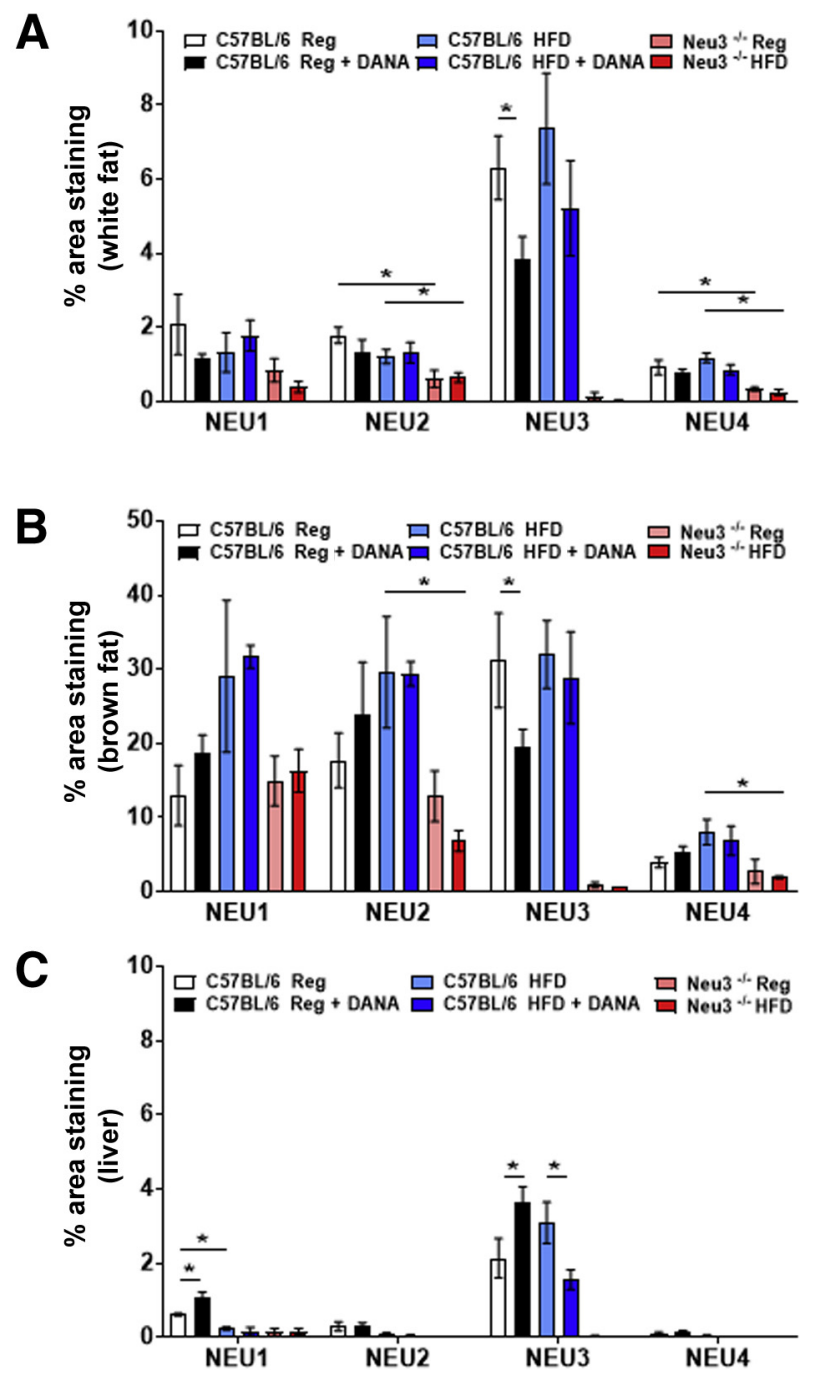

Figure $9 \mathrm{~N}$-acetyl-2,3-dehydro-2-deoxyneuraminic acid (DANA) injections or loss of neuraminidase (NEU) 3 reduces high-fat diet (HFD)induced changes in sialidase expression. Sections of white fat $(\mathbf{A})$, brown fat (B), or liver (C) were stained with antibodies against NEU1, NEU2, NEU3, and NEU4. Graphs show quantification of percentage tissue area stained with antibodies. Data are expressed as means \pm SEM. $n=3$ to 4 mice per group. ${ }^{\star} P<0.05$ (one-way analysis of variance, Sidak test). Reg, regular diet.

\section{Discussion}

Both injections of DANA and loss of NEU3 were found to improve multiple features of high-fat diet-induced obesity in mice. Injections of the general sialidase inhibitor DANA moderate weight gain, attenuate elevated glucose levels, reduce liver steatosis, and decrease adipose and liver inflammation. Compared with C57BL/6 mice on HFD, $\mathrm{Neu}^{-/-}$mice had reduced HFD-induced adipose and liver inflammation. These data suggest that DANA can decrease adipose tissue and liver inflammation, and $\mathrm{Neu}^{-/-}$mice are resistant to HFD-induced adipose tissue and liver inflammation. The observation that DANA can inhibit weight gain and reduce steatosis, whereas $\mathrm{Neu} 3^{-/-}$ mice are not resistant to HFD-induced weight gain and steatosis, indicates that DANA acts on more than one sialidase, whereas the genetic loss of NEU3 indicates that this enzyme is important for regulating inflammation. Both DANA and loss of NEU3 reduced the numbers of Mac2-positive macrophages that aggregate into crown-like structures and tissue-resident F4/80-positive macrophages. There were fewer CD64-, F4/80-, and Mac2-positive cells present in the adipose tissue of $\mathrm{Neu}^{-/-}$mice on either regular or HFD, compared with C57BL/6 mice. DANA also reduced the accumulation of lipids in adipocyte cultures, and both DANA and loss of NEU3 inhibited the accumulation of lipids in brown adipose tissue. DANA and loss of NEU3 also attenuated HFD-induced changes in brown fat UCP1 expression. In the liver, both DANA and loss of NEU3 reduced the HFD-induced increase in F4/80-positive but not CD64- and Mac2-positive macrophages. DANA, but not NEU3, also reduced liver steatosis. The effects of DANA and loss of NEU3 appear to be mostly independent of serum ALT, AST, and cytokines, and the levels of sialidase proteins in the adipose and liver tissues.

The role of sialidases in the regulation of HFD-induced changes in physiology and immunology is unclear. Compared with nonobese control mice $(\mathrm{db} /+)$, obese $(\mathrm{db} /$ db) mice on a regular diet have reduced NEU1 mRNA levels and reduced NEU1 enzyme activity in liver tissue, but increased NEU1 enzyme activity in epididymal white fat. ${ }^{17}$ Compared with lean $(\mathrm{Fa} / \mathrm{fa})$ Zucker rats, obese (fa/ fa) Zucker rats (which develop obesity without diabetes) on a regular diet have reduced NEU3 protein content in the soleus muscle and liver. ${ }^{18}$ Wistar rats fed a high-fat diet also have reduced NEU3 protein levels in white fat compared with regular diet controls. ${ }^{18}$ Compared with nonobese humans, obese patients have higher NEU3 mRNA in the small intestine. NEU3 protein was also increased in the small intestines of HFD-treated mice compared with regular diet mice. ${ }^{59}$ In addition, oral administration of the sialidase inhibitor DANA to mice inhibited NEU3 enzyme activity in the small intestine, but not in the liver and white adipose tissue, and attenuated hepatic steatosis and HFD-induced weight gain. ${ }^{59}$ NEU3 overexpression in the liver using adenovirus improved glucose tolerance and insulin sensitivity, but increased hepatic triglyceride and glycogen accumulation and induced hyperlipidemia. ${ }^{19}$ These data indicate that DANA and loss of NEU3 also have a complex effect on sialidase protein levels, indicating that other systems may also be altered by DANA or loss of NEU3. Together, these results suggest a complex association between obesity and sialidases.

Altered sialidase levels can lead to altered insulin signaling. ${ }^{18,19,60-62}$ NEU1 can desialylate both insulin and insulin-like growth factor 1 receptors, leading to increased insulin receptor signaling. ${ }^{61-63}$ Long-term 
hepatic NEU1 overexpression increases glucose intolerance and insulin resistance in mice on an HFD. ${ }^{63}$ Reduced liver NEU3 protein levels lead to reduced insulin signaling, ${ }^{18}$ whereas increased NEU3 protein in the liver increases insulin sensitivity and glucose tolerance in mice. ${ }^{19,64}$ These data suggest that the dysregulation of insulin, glucose, lipids, and inflammation in obesity may be further impacted by changes in sialidase expression and activity.

Obesity is also associated with inflammation, especially the accumulation of macrophages. ${ }^{8,31,51,52}$ Both DANA and loss of NEU3 leads to a lower density of Mac2- and F4/80positive macrophages in both adipose tissue and liver. Under steady-state conditions, tissue-resident adipose macrophages express CD64 and F4/80, whereas inflammatory macrophages express Mac2. ${ }^{38-41}$ The observation that HFD-induced increases in F4/80- and Mac2-positive cells in adipose tissue were reversed by DANA suggests that sialidases affect adipose tissue inflammation. Compared with control mice, $\mathrm{Neu} 3^{-/-}$mice had significantly lower numbers of CD64-, F4/80-, and Mac2-positive cells in white adipose tissue, even on a regular diet. However, no difference in lung macrophage populations was found between control and $\mathrm{Neu}^{-/-}$mice. ${ }^{16}$ A possible explanation points to the differential expression of sialidases in the two tissues. ${ }^{58}$ These data suggest that NEU3 has different effects in different tissues, and affects adipose tissue monocyte/ macrophage biology.

The liver also has tissue-resident and inflammatory macrophages. ${ }^{53,54,65,66}$ As expected, HFD led to an increase in macrophage numbers in the liver, but DANA only decreased $\mathrm{F} 4 / 80^{+}$resident, but not $\mathrm{CD}^{+}{ }^{+}$resident or $\mathrm{Mac}^{+}$inflammatory macrophages. Compared with C57BL/ 6 mice, $\mathrm{Neu}^{-1-}$ mice had significantly lower numbers of CD64- and Mac2-, but not F4/80-positive cells in the liver on regular and high-fat diets. These observations suggest that sialidases regulate at least some of the five recognized liver macrophage populations. ${ }^{53}$ Together, these data suggest that one function of sialidases, especially NEU3, is to regulate adipose and liver tissue inflammation, and that sialidase inhibitors are potential therapeutics for high-fat diet-induced inflammation.

\section{Acknowledgments}

We thank Jamey Marth and Douglas Heithoff (University of California, Santa Barbara) for sending $\mathrm{Neu} 3^{-/-}$knockout mice; Chaodong $\mathrm{Wu}$ for helpful discussions; and the Laboratory Animal Resources and Research staff (Texas A\&M University) for animal care.

\section{Supplemental Data}

Supplemental material for this article can be found at http://doi.org/10.1016/j.ajpath.2020.09.011.

\section{References}

1. Danaei G, Ding EL, Mozaffarian D, Taylor B, Rehm J, Murray CJL, Ezzati M: The preventable causes of death in the United States: comparative risk assessment of dietary, lifestyle, and metabolic risk factors. PLoS Med 2009, 6:e1000058

2. Kim DD, Basu A: Estimating the medical care costs of obesity in the United States: systematic review, meta-analysis, and empirical analysis. Value Health 2016, 19:602-613

3. Flegal KM, Kruszon-Moran D, Carroll MD, Fryar CD, Ogden CL: Trends in obesity among adults in the United States, 2005 to 2014. JAMA 2016, 315:2284-2291

4. Spengler EK, Loomba R: Recommendations for diagnosis, referral for liver biopsy, and treatment of nonalcoholic fatty liver disease and nonalcoholic steatohepatitis. Mayo Clin Proc 2015, 90:1233-1246

5. Estes C, Anstee QM, Arias-Loste MT, Bantel H, Bellentani S, Caballeria J, Colombo M, Craxi A, Crespo J, Day CP, Eguchi Y, Geier A, Kondili LA, Kroy DC, Lazarus JV, Loomba R, Manns MP, Marchesini G, Nakajima A, Negro F, Petta S, Ratziu V, RomeroGomez M, Sanyal A, Schattenberg JM, Tacke F, Tanaka J, Trautwein C, Wei L, Zeuzem S, Razavi H: Modeling NAFLD disease burden in China, France, Germany, Italy, Japan, Spain, United Kingdom, and United States for the period 2016-2030. J Hepatol 2018, 69:896-904

6. Abeysekera KWM, Fernandes GS, Hammerton G, Portal AJ, Gordon FH, Heron J, Hickman M: Prevalence of steatosis and fibrosis in young adults in the UK: a population-based study. Lancet Gastroenterol Hepatol 2020, 5:295-305

7. Marengo A, Jouness RIK, Bugianesi E: Progression and natural history of nonalcoholic fatty liver disease in adults. Clin Liver Dis 2016, 20:313-324

8. Lackey DE, Olefsky JM: Regulation of metabolism by the innate immune system. Nat Rev Endocrinol 2015, 12:15

9. Crewe C, An YA, Scherer PE: The ominous triad of adipose tissue dysfunction: inflammation, fibrosis, and impaired angiogenesis. J Clin Invest 2017, 127:74-82

10. Strissel KJ, Stancheva Z, Miyoshi H, Perfield JW 2nd, DeFuria J, Jick Z, Greenberg AS, Obin MS: Adipocyte death, adipose tissue remodeling, and obesity complications. Diabetes 2007, 56: 2910-2918

11. Osborn O, Olefsky JM: The cellular and signaling networks linking the immune system and metabolism in disease. Nat Med 2012, 18: 363

12. Pshezhetsky AV, Ashmarina LI: Desialylation of surface receptors as a new dimension in cell signaling. Biochem Biokhim 2013, 78 : $736-745$

13. Monti E, Miyagi T: Structure and function of mammalian sialidases. Top Curr Chem 2015, 366:183-208

14. Magesh S, Moriya S, Suzuki T, Miyagi T, Ishida H, Kiso M: Design, synthesis, and biological evaluation of human sialidase inhibitors, part 1: selective inhibitors of lysosomal sialidase (NEU1). Bioorg Med Chem Lett 2008, 18:532-537

15. Karhadkar TR, Pilling D, Cox N, Gomer RH: Sialidase inhibitors attenuate pulmonary fibrosis in a mouse model. Sci Rep 2017, 7 : 15069

16. Karhadkar TR, Chen W, Gomer RH: Attenuated pulmonary fibrosis in sialidase-3 knockout (Neu3(-/-)) mice. Am J Physiol Lung Cell Mol Physiol 2020, 318:L165-L179

17. Natori Y, Ohkura N, Nasui M, Atsumi G, Kihara-Negishi F: Acidic sialidase activity is aberrant in obese and diabetic mice. Biol Pharm Bull 2013, 36:1027-1031

18. Lipina C, Nardi F, Grace H, Hundal HS: NEU3 sialidase as a marker of insulin sensitivity: regulation by fatty acids. Cell Signal 2015, 27: $1742-1750$

19. Yoshizumi S, Suzuki S, Hirai M, Hinokio Y, Yamada T, Yamada T, Tsunoda U, Aburatani H, Yamaguchi K, Miyagi T, Oka Y: Increased 
hepatic expression of ganglioside-specific sialidase, NEU3, improves insulin sensitivity and glucose tolerance in mice. Metabolism 2007, $56: 420-429$

20. Yamaguchi K, Shiozaki K, Moriya S, Koseki K, Wada T, Tateno H, Sato I, Asano M, Iwakura Y, Miyagi T: Reduced susceptibility to colitis-associated colon carcinogenesis in mice lacking plasma membrane-associated sialidase. PLoS One 2012, 7:e41132

21. Pilling D, Cox N, Thomson MA, Karhadkar TR, Gomer RH: Serum amyloid $\mathrm{P}$ and a dendritic cell specific intercellular adhesion molecule-3 grabbing nonintegrin ligand inhibit high-fat diet induced adipose tissue and liver inflammation and steatosis in mice. Am J Pathol 2019, 189:2400-2413

22. American Veterinary Medical Association: AVMA Guidelines for the Euthanasia of Animals. Schaumburg, IL: American Veterinary Medical Association, 2013

23. Mehlem A, Hagberg CE, Muhl L, Eriksson U, Falkevall A: Imaging of neutral lipids by oil red $\mathrm{O}$ for analyzing the metabolic status in health and disease. Nat Protoc 2013, 8:1149-1154

24. Pilling D, Gomer RH: Persistent lung inflammation and fibrosis in serum amyloid P component (Apcs -/-) knockout mice. PLoS One 2014, 9:e93730

25. Herlihy SE, Brown ML, Pilling D, Weeks BR, Myers LK, Gomer RH: Role of the neutrophil chemorepellent soluble dipeptidyl peptidase IV in decreasing inflammation in a murine model of arthritis. Arthritis Rheumatol 2015, 67:2634-2638

26. Church C, Berry R, Rodeheffer MS: Isolation and study of adipocyte precursors. Methods Enzymol 2014, 537:31-46

27. Liu L, Zheng LD, Donnelly SR, Emont MP, Wu J, Cheng Z: Isolation of mouse stromal vascular cells for monolayer culture. Methods Mol Biol 2017, 1566:9-16

28. Rueden CT, Schindelin J, Hiner MC, DeZonia BE, Walter AE, Arena ET, Eliceiri KW: ImageJ2: ImageJ for the next generation of scientific image data. BMC Bioinformatics 2017, 18:529

29. Pilling D, Roife D, Wang M, Ronkainen SD, Crawford JR, Travis EL, Gomer RH: Reduction of bleomycin-induced pulmonary fibrosis by serum amyloid P. J Immunol 2007, 179:4035-4044

30. Galarraga M, Campión J, Muñoz-Barrutia A, Boqué N, Moreno H, Martínez JA, Milagro F, Ortiz-de-Solórzano C: Adiposoft: automated software for the analysis of white adipose tissue cellularity in histological sections. J Lipid Res 2012, 53:2791-2796

31. Lumeng CN, Saltiel AR: Inflammatory links between obesity and metabolic disease. J Clin Invest 2011, 121:2111-2117

32. Van Gaal L, Dirinck E: Pharmacological approaches in the treatment and maintenance of weight loss. Diabetes Care 2016, 39:S260

33. Ivanov S, Merlin J, Lee MKS, Murphy AJ, Guinamard RR: Biology and function of adipose tissue macrophages, dendritic cells and B cells. Atherosclerosis 2018, 271:102-110

34. Sun K, Kusminski CM, Scherer PE: Adipose tissue remodeling and obesity. J Clin Invest 2011, 121:2094-2101

35. Sanchez-Gurmaches J, Hung C-M, Guertin DA: Emerging complexities in adipocyte origins and identity. Trends Cell Biol 2016, 26: 313-326

36. Shaul ME, Bennett G, Strissel KJ, Greenberg AS, Obin MS: Dynamic, M2-like remodeling phenotypes of $\mathrm{CD} 11 \mathrm{c}+$ adipose tissue macrophages during high-fat diet-induced obesity in mice. Diabetes 2010, 59:1171-1181

37. Bremer AA, Devaraj S, Afify A, Jialal I: Adipose tissue dysregulation in patients with metabolic syndrome. J Clin Endocrinol Metab 2011, 96:E1782-E1788

38. Asterholm IW, McDonald J, Blanchard PG, Sinha M, Xiao Q, Mistry J, Rutkowski JM, Deshaies Y, Brekken RA, Scherer PE: Lack of "immunological fitness" during fasting in metabolically challenged animals. J Lipid Res 2012, 53:1254-1267

39. Cho KW, Zamarron BF, Muir LA, Singer K, Porsche CE, DelProposto JB, Geletka L, Meyer KA, O’Rourke RW, Lumeng CN: Adipose tissue dendritic cells are independent contributors to obesityinduced inflammation and insulin resistance. J Immunol 2016, 197 : $3650-3661$
40. Ringling RE, Gastecki ML, Woodford ML, Lum-Naihe KJ, Grant RW, Pulakat L, Vieira-Potter VJ, Padilla J: Loss of Nlrp3 does not protect mice from western diet-induced adipose tissue inflammation and glucose intolerance. PLoS One 2016, 11:e0161939

41. Hill DA, Lim H-W, Kim YH, Ho WY, Foong YH, Nelson VL, Nguyen HCB, Chegireddy K, Kim J, Habertheuer A, Vallabhajosyula P, Kambayashi T, Won K-J, Lazar MA: Distinct macrophage populations direct inflammatory versus physiological changes in adipose tissue. Proc Natl Acad Sci U S A 2018, 115:E5096

42. Weisberg SP, McCann D, Desai M, Rosenbaum M, Leibel RL, Ferrante AW Jr: Obesity is associated with macrophage accumulation in adipose tissue. J Clin Invest 2003, 112:1796-1808

43. Lumeng CN, Bodzin JL, Saltiel AR: Obesity induces a phenotypic switch in adipose tissue macrophage polarization. J Clin Invest 2007, 117:175-184

44. Wang S, Song R, Wang Z, Jing Z, Wang S, Ma J: S100A8/A9 in inflammation. Front Immunol 2018, 9:1298

45. Sztalryd C, Brasaemle DL: The perilipin family of lipid droplet proteins: gatekeepers of intracellular lipolysis. Biochim Biophys Acta Mol Cell Biol Lipids 2017, 1862:1221-1232

46. Alcalá M, Calderon-Dominguez M, Bustos E, Ramos P, Casals N, Serra D, Viana M, Herrero L: Increased inflammation, oxidative stress and mitochondrial respiration in brown adipose tissue from obese mice. Sci Rep 2017, 7:16082

47. Richard D, Picard F: Brown fat biology and thermogenesis. Front Biosci (Landmark Ed) 2011, 16:1233-1260

48. Seale P: Brown adipose tissue biology and therapeutic potential. Front Endocrinol 2013, 4:14

49. Chalasani N, Younossi Z, Lavine JE, Charlton M, Cusi K, Rinella M, Harrison SA, Brunt EM, Sanyal AJ: The diagnosis and management of nonalcoholic fatty liver disease: practice guidance from the American Association for the Study of Liver Diseases. Hepatology 2017, 67:328-357

50. Sumida Y, Yoneda M: Current and future pharmacological therapies for NAFLD/NASH. J Gastroenterol 2018, 53:362-376

51. Brempelis KJ, Crispe IN: Infiltrating monocytes in liver injury and repair. Clin Trans Immunol 2016, 5:e113

52. Takahashi Y, Fukusato T: Histopathology of nonalcoholic fatty liver disease/nonalcoholic steatohepatitis. World J Gastroenterol 2014, 20 : 15539-15548

53. Scott CL, T'Jonck W, Martens L, Todorov H, Sichien D, Soen B, Bonnardel J, De Prijck S, Vandamme N, Cannoodt R, Saelens W, Vanneste B, Toussaint W, De Bleser P, Takahashi N, Vandenabeele P, Henri S, Pridans C, Hume DA, Lambrecht BN, De Baetselier P, Milling SWF, Van Ginderachter JA, Malissen B, Berx G, Beschin A, Saeys Y, Guilliams M: The transcription factor ZEB2 is required to maintain the tissue-specific identities of macrophages. Immunity 2018, 49:312-325.e5

54. Scott CL, Zheng F, De Baetselier P, Martens L, Saeys Y, De Prijck S, Lippens S, Abels C, Schoonooghe S, Raes G, Devoogdt N, Lambrecht BN, Beschin A, Guilliams M: Bone marrow-derived monocytes give rise to self-renewing and fully differentiated Kupffer cells. Nat Commun 2016, 7:10321

55. Devisscher L, Scott CL, Lefere S, Raevens S, Bogaerts E, Paridaens A, Verhelst X, Geerts A, Guilliams M, Van Vlierberghe H: Non-alcoholic steatohepatitis induces transient changes within the liver macrophage pool. Cell Immunol 2017, 322:74-83

56. Monti E, Bonten E, D’Azzo A, Bresciani R, Venerando B, Borsani G, Schauer R, Tettamanti G: Sialidases in vertebrates: a family of enzymes tailored for several cell functions. Advances in Carbohydrate Chemistry and Biochemistry. Edited by Derek H. Cambridge, MA: Academic Press, 2010, pp. 403-479

57. White EJ, Gyulay G, Lhoták Š, Szewczyk MM, Chong T, Fuller MT, Dadoo O, Fox-Robichaud AE, Austin RC, Trigatti BL, Igdoura SA: Sialidase down-regulation reduces non-HDL cholesterol, inhibits leukocyte transmigration, and attenuates atherosclerosis in ApoE knockout mice. J Biol Chem 2018, 293:14689-14706 
58. Miyagi T, Yamaguchi K: Mammalian sialidases: physiological and pathological roles in cellular functions. Glycobiology 2012, 22: 880-896

59. Xie C, Yagai T, Luo Y, Liang X, Chen T, Wang Q, Sun D, Zhao J, Ramakrishnan SK, Sun L, Jiang C, Xue X, Tian Y, Krausz KW, Patterson AD, Shah YM, Wu Y, Jiang C, Gonzalez FJ: Activation of intestinal hypoxia-inducible factor 2alpha during obesity contributes to hepatic steatosis. Nat Med 2017, 23:1298-1308

60. Hinek A, Bodnaruk TD, Bunda S, Wang Y, Liu K: Neuraminidase-1, a subunit of the cell surface elastin receptor, desialylates and functionally inactivates adjacent receptors interacting with the mitogenic growth factors PDGF-BB and IGF-2. Am J Pathol 2008, 173:1042-1056

61. Arabkhari M, Bunda S, Wang Y, Wang A, Pshezhetsky AV, Hinek A: Desialylation of insulin receptors and IGF-1 receptors by neuraminidase-1 controls the net proliferative response of L6 myoblasts to insulin. Glycobiology 2010, 20:603-616

62. Dridi L, Seyrantepe V, Fougerat A, Pan X, Bonneil E, Thibault P, Moreau A, Mitchell GA, Heveker N, Cairo CW, Issad T, Hinek A, Pshezhetsky AV: Positive regulation of insulin signaling by neuraminidase 1. Diabetes 2013, 62:2338-2346
63. Fougerat A, Pan X, Smutova V, Heveker N, Cairo CW, Issad T, Larrivee B, Medin JA, Pshezhetsky AV: Neuraminidase 1 activates insulin receptor and reverses insulin resistance in obese mice. Mol Metab 2018, 12:76-88

64. Sasaki A, Hata K, Suzuki S, Sawada M, Wada T, Yamaguchi K, Obinata M, Tateno H, Suzuki H, Miyagi T: Overexpression of plasma membrane-associated sialidase attenuates insulin signaling in transgenic mice. J Biol Chem 2003, 278:27896-27902

65. David BA, Rezende RM, Antunes MM, Santos MM, Freitas Lopes MA, Diniz AB, Sousa Pereira RV, Marchesi SC, Alvarenga DM, Nakagaki BN, Araújo AM, dos Reis DS, Rocha RM, Marques PE, Lee W-Y, Deniset J, Liew PX, Rubino S, Cox L, Pinho V, Cunha TM, Fernandes GR, Oliveira AG, Teixeira MM, Kubes P, Menezes GB: Combination of mass cytometry and imaging analysis reveals origin, location, and functional repopulation of liver myeloid cells in mice. Gastroenterology 2016, 151:1176-1191

66. Gomez Perdiguero E, Klapproth K, Schulz C, Busch K, Azzoni E, Crozet L, Garner H, Trouillet C, de Bruijn MF, Geissmann F, Rodewald HR: Tissue-resident macrophages originate from yolk-sacderived erythro-myeloid progenitors. Nature 2015, 518:547-551 